\title{
DA OBSCURIDADE À EMANCIPAÇÃO: UM OLHAR SOBRE O LEITOR
}

\author{
Wellingson Valente dos REIS \\ José Guilherme de Oliveira CASTRO
}

\section{RESUMO}

Este estudo tem como objetivo traçar alguns momentos históricos da emancipação do leitor na literatura. Para isso, busca-se perceber os elementos valorizados no circuito literário em cada época de produção, começando na idade clássica, quando a valorização maior era do autor (escritor/narrador), ou seja, daquele que contava as histórias Com o passar do tempo essa importância passou a ser da obra, como nos casos de Dom Quixote e de Os Sofrimentos do Jovem Werther, até ser deslocada às teorias que passaram a destacar a importância do leitor para a história da literatura, colocando-o no circuito literário (Estética da Recepção). Por fim, chegou-se na igualdade entre autor, obra e leitor, além disso se estabelece uma relação entre a emancipação do leitor e o ensino de literatura no âmbito escolar A análise do processo de emancipação do leitor na história da literatura aqui realizada teve como principais referências os estudos de arte e política de Rancière $(2009,2012)$, os estudos de estética da recepção, leitor e literatura realizados por Iser (1996,2011), Jauss (1994), Compagnon (2003), Zilberman (1989, 2000), Eco (2005) entre outros. Acompanhou-se o processo histórico ao longo do qual o leitor precisou se emancipar e sair do seu local de passividade para se tornar sujeito ativo no processo de construção da literatura.

PALAVRAS- CHAVE: Leitor; Emancipação; Literatura.

FROM DARKNESS TO EMANCIPATION: A LOOK AT THE READER

\begin{abstract}
This study aims to make objective to trace some historical moments of the reader's emancipation in the literature. In order to do so, it is sought to perceive the elements valued in the literary circuit in each production period, beginning in the classical age, when the greatest value was given to the author (writer/narrator), that is, to the one who told the stories. Along time, this importance came to be given to the work, as in the cases of Don Quixote and The Sufferings of the Young Werther, until it came to be displaced to the theories that came to emphasize the importance of the reader for the history of literature, placing him in the literary circuit (Aesthetics Reception). Finally, it has come to the equality among author, work and reader. In addition, a relationship is established between the emancipation of the reader and the teaching of literature in the school environment. The analysis of the process of emancipation of the reader in the history of the literature here carried out had as main references the studies of art and politics of Rancière (2009, 2012), the studies of aesthetics reception, reader and literature carried out by Iser (1996, 2011), Jauss (1994), Compagnon (2003), Zilberman (1989, 2000), Eco (2005) among others. It was traced the historical process along which the reader had to emancipate himself and leave his place of passivity to become an active subject in the process of construction of literature.
\end{abstract}

KEYWORDS: Reader; Emancipation; Literature.

\section{DE LA OSCURIDAD A LA EMANCIPACIÓN: UNA MIRADA SOBRE EL LECTOR}

\section{RESUMEN:}

Este estudio tiene como objetivo rastrear algunos momentos históricos de la emancipación del lector en la literatura. Para ello, se busca percibir los elementos valorados en el circuito literario en cada época de producción, empezando en la edad clásica, cuando la valorización mayor era del autor (escritor / narrador), o sea, del que contaba las historias. Con el paso del tiempo la importancia pasó a ser de la obra, como en los casos de Don Quijote y de Las penas del joven Werther, hasta ser desplazada a las teorías que pasaron a destacar la importancia del lector para la historia de la literatura, colocándolo en el circuito literario (Estética de la recepción). Por fin, se llegó en la igualdad entre autor, obra

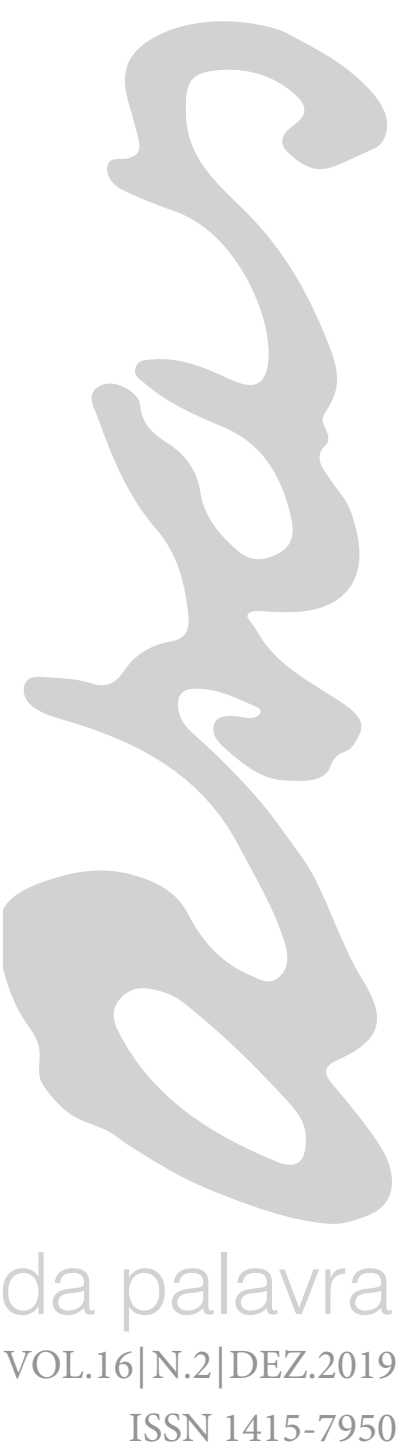


y lector. Además, se establece una relación entre la emancipación del lector y la enseñanza de la literatura en el entorno escolar. El análisis del proceso de emancipación del lector en la historia de la literatura aquí realizada tuvo como principales referencias los estudios de arte y politica de Rancière (2009, 2012), los estudios de estética de la recepción, lector y literatura realizados por Iser (1996,2011), Jauss (1994), Compagnon (2003), Zilberman (1989, 2000), Eco (2005) entre otros. Se acompañó el proceso histórico a lo largo del cual el lector necesitó emanciparse y salir de su lugar de pasividad para convertirse en sujeto activo en el proceso de construcción de la literatura.

PALABRAS CLAVE: Lector; Emancipación; La literatura.

\section{INTRODUÇÃO}

Pensar hoje a literatura sem a figura do leitor parece ser algo improvável, porém muita coisa aconteceu na história e na teoria literária para que o leitor pudesse ser valorizado como parte integrante do sistema da literatura.

Este texto reflete acerca da luta política em torno da emancipação do leitor, que durante todo o processo de criação literária esteve presente no circuito da literatura como mero receptáculo, ou seja, aquele que tinha o papel de receber as informações idealizadas pelo autor repassadas pelo livro, aquele que seria influenciado pelas perspectivas presentes nas obras.

A seguir, examinamos alguns momentos históricos em que o leitor se emancipou e se tornou tão importante para a literatura, como qualquer outro componente do sistema literário, e terminamos apresentando uma pequena visão acerca de como essa modificação na perspectiva do leitor também mudou a visão de leitura que se possui hoje.

\section{HISTÓRIA DO LEITOR E DA LITERATURA}

A literatura é uma invenção humana que data desde os tempos clássicos. Ela sempre teve como materialização a escrita e, como objetivo, refletir questões humanas, tanto que Platão considerava a literatura perigosa, já que os livros falsificariam a realidade e conduziriam a um saber artificial e indesejado pela filosofia, que seria o saber reflexivo.

$\mathrm{Na}$ Grécia antiga, havia uma valorização da figura do narrador. Ele, junto com o autor, eram as figuras mais valorizadas da literatura da época, tanto que os Aedos passaram a ser considerados pessoas de extrema importância para a manutenção do texto literário. Esse narrador será aquele chamado por Benjamin (1994) de narrador-experiência, e a 
REVISTA DO PROGRAMA DE PÓS-GRADUAÇÃO EM COMUNICAÇÃO, LINGUAGENS E CULTURA DA UNIVERSIDADE DA AMAZÔNIA

experiência é a "matéria da tradição, tanto na vida privada quando na coletiva" (Benjamin, 1994, p. 105). A experiência se sustenta, por isso mesmo, na tradição ritual, litúrgica, na magia. Assim sendo, o narrador é de extrema importância porque carrega consigo um saber peculiar, que vai além do saber dos outros, algo aurático.

$\mathrm{Na}$ antiguidade clássica, o autor das histórias tinha um grande valor social, pois, normalmente, era convidado para fazer parte da corte, mas a figura central era o narrador, porque ele deveria "decorar" as poesias para depois transmiti-las oralmente. Os narradores, portanto, detinham o poder do narrar, o poder de contar histórias, o poder da literatura na sua época - e por isso eram tão importantes.

$\mathrm{Na}$ idade média chama a atenção a história de um cavaleiro errante que ficou conhecido como Dom Quixote. Nesta obra, temos a presença de um personagem obcecado em livros, tanto que prefere a presença dos livros do que das pessoas. No entanto, o que mais chama a atenção é a questão do homem que deixa de ser ele mesmo para se tornar uma outra pessoa sob influência do livro. O poder do livro é tão grande sobre o leitor que há um apagamento do ser pela loucura e a construção de um outro self.

De acordo com Mead (1967), o self é constituído tanto pelo "eu" quanto pelo "outro". O indivíduo só se entende enquanto self quando é capaz de reconhecer os outros e reconhecer a si mesmo nos outros, tornando-se, assim, "um objeto para ele mesmo" (Mead, 1967, p. 95). A noção de "eu” ("I"), por sua vez, é uma fase do self, é sua instância mais psicológica e interna, e objeto de estudo da Psicologia, sobre o qual não iremos nos debruçar.

O conceito de flexibilidade do self de Mead (1967), é um dos pontos mais importantes para a literatura, pois permite reconhecer que, dentre as individualidades - diversas, mutáveis e passíveis de serem criadas -, é possível perceber as potencialidades criadoras do homem. Assim, um novo dado é acrescentado à reflexão sobre a dupla condição humana, de criador e criatura, noção presente em Dom Quixote, em que o fidalgo é criador de suas histórias e criatura controlada pelo livro. Em tal contexto, o leitor é simplesmente apagado de sua realidade e levado a não se reconhecer como tal, o que o leva à loucura, mostrando que, para a época, a força da literatura estava na obra, tanto que ela tinha a força necessária para reconstruir o leitor.

Quando avançamos para a modernidade, nos deparamos ainda 
com o dito "poder" do livro sobre o leitor. Agora, em um caso real, não mais em relação a um personagem que foi influenciado pelo livro, como o que ocorreu com os leitores de Os sofrimentos do Jovem Werther, quando os periódicos da época mostraram vários casos de leitores que se suicidaram após a leitura da obra, o que destaca o poder do livro para o bem ou para o mal, mostrando o quanto ele poderia ser perigoso.

Quando passamos a observar essa análise pelo viés da teoria literária, percebemos que alguns estudos literários se opõem radicalmente entre si. Em alguns casos, o leitor é radicalmente excluído e, em outros, supervalorizado, tanto que é colocado como o principal elemento do sistema literário. Para que se chegasse a esse patamar, no entanto, uma grande luta política se estabeleceu diante do papel do leitor na literatura.

Durante muito tempo, o historicismo, o formalismo e o $\mathrm{New}$ Criticism, correntes de analises literárias, ignoravam o leitor porque defendiam a obra literária como uma unidade autossuficiente. $\mathrm{O}$ poema, por exemplo, existe por si só, como um monumento verbal, desprendido de seu autor e de seu leitor. $\mathrm{O}$ autor ainda tinha alguma importância, exatamente por ser o produtor daquele texto; já o leitor, todas as correntes concordavam em bani-lo, pois consideravam suas faculdades interpretativas muito limitadas, atribuindo a ele, a má compreensão e as falhas da leitura. O leitor ideal seria, pois, aquele que se curva à expectativa do texto, que é passivo ao texto, lendo e interpretando fielmente o que está escrito.

O New Criticism defendia uma leitura analítica do texto, uma preocupação com a estrutura e com a objetividade do texto, ou seja, a obra deveria atingir um fim, cabendo ao leitor apenas acompanhar o raciocínio e ser conduzido. O leitor não podia sair do texto, a leitura devia ser fechada, a interpretação deveria ser apenas com base na obra, ou seja, em si mesma.

Outras correntes também trataram o leitor de forma semelhante. O estruturalismo buscava entender o objeto de estudo como um todo, em uma relação sistêmica e funcional, os formalistas colocavam todo o peso nos livros, nos códigos, argumentando que qualquer leitor seria capaz de decifrá-los, e os positivistas desejavam o rigor científico como método de leituras. A Narratologia e a poética chegam a atribuir um papel para o leitor, que não é muito diferente do pensamento acima: um leitor abstrato ou perfeito, com o qual nenhum leitor real poderia se identificar. 


\section{EMANCIPAÇÃO DO LEITOR}

O pensamento extremamente limitador das correntes expostas anteriormente nos faz remeter ao entendimento do professor de estética e política, Jacques Rancière, em A partilha do sensível (2009, p. 16-17), segundo o qual a estética seria "um sistema de formas a priori determinando, o que se dá a sentir. É um recorte dos tempos e dos espaços, do visível e do invisível, da palavra e do ruído que define ao mesmo tempo o lugar e o que está em jogo na política como forma de experiência" Assim sendo, durante muito tempo se propôs que a estética literária não valorizasse o leitor e, no entanto, isso precisaria mudar - para Rancière (2009), "a política ocupa-se do que se vê e do que se pode dizer sobre o que é visto, de quem tem competência para ver e qualidade para dizer, das propriedades do espaço e dos possíveis do tempo." (Rancière, 2009, p.17).

Em $O$ espectador Emancipado, Rancière (2012) formula o que ele chama de paradoxo do espectador, um paradoxo que está baseado em um regime de sensibilidade e produção estética, o que, por similitudes, podemos aproximar ao paradoxo do leitor, pois este também passa pelo momento da fruição estética. Esse paradoxo parte de duas premissas. A primeira, que perdurou em várias correntes da teoria literária, afirma que o espectador (leitor) é o contrário do conhecer, entende que o mesmo desconhece a realidade do processo de produção da aparência que é colocada diante dele no espetáculo (leitura). A segunda premissa, por outro lado, apresenta o espectador (leitor) como o contrário do agir, pois cabe a ele permanecer imóvel diante do que lhe é apresentado. O paradoxo instala-se uma vez que "não existe teatro sem espectador" (RANCIÈRE, 2012, p. 8), assim como não existe literatura sem seus leitores.

Para Rancière (2012), a dedução mais lógica que decorre do paradoxo sobre o espectador (leitor) é a de que o teatro (literatura) seria uma cena de ilusão e passividade, assim como o ato de ler também seria. Neste sentido, o leitor, quando estivesse lendo, estaria simplesmente decodificando as ideias do autor, aquele que detêm o conhecimento, de maneira passiva, sem poder reagir a essas ideias. Platão, colocado na origem dessa visão, considerava a mímese teatral como o lugar em que ignorantes vão assistir sofredores. Para o filósofo grego, a comunidade coreográfica, Khorea, na qual todos participavam ativamente, era o oposto ao teatro. 
Fazendo referência a sua obra $O$ mestre Ignorante, Rancière (2012) fala do papel dos pedagogos junto aos alunos, que é o papel de embrutecimento, pois, segundo ele, o método tradicional de ensino que conhecemos tem o mestre como alguém que irá nos explicar tudo aquilo que está escrito em livros. O mestre explica, questiona, exemplifica e desfaz qualquer dúvida que possa surgir durante o estudo. A princípio, isso pode parecer uma boa coisa ou até mesmo um passo para o progresso do aluno, mas esse mestre explicador traz consigo muitos problemas.

O principal problema acarretado pelo mestre explicador é a acomodação que pode gerar no raciocínio do aluno, que não sentirá mais prazer em buscar, pesquisar respostas para as suas dúvidas e angústias. Algo similar ocorre com o papel dos críticos e dos editores, que muitas vezes não se entendem como leitores e não entendem que suas leituras são extremamente influenciadoras, pois são capazes de definir o sucesso ou não de uma obra, criando tendências literárias e ao mesmo tempo gerando uma acomodação do leitor para a busca de novidades.

Entre autor e leitor há, às vezes, um longo caminho a ser percorrido por uma obra, e os editores costumam desempenhar um papel essencial nesse circuito literário, pois são eles que selecionam as obras a serem publicadas, muitas vezes adaptando-as conforme o público que lhe é previsto. Papel semelhante possui o crítico que, em vários momentos, ao fazer uma dura crítica a uma obra, acaba por afastar possíveis leitores do texto, levando-a a um "limbo" literário.

Esse papel realizado pelos críticos e editores, para Rancière (2012), é um papel embrutecedor, já que acaba por limitar as opções dos leitores, mudando ou ditando regras que privilegiam obras que as seguem, e criando leitores específicos para aquele tipo de obra, e não entendendo que o leitor é livre para fazer suas escolhas devido à emancipação intelectual das pessoas, pois, afinal, ler também é escolher e agir.

O leitor, assim como o aluno, também age selecionando, comparando e interpretando. Além disso, Rancière (2012) critica a noção de que a ação do leitor é pré-determinada pelo artista, como prega a lógica do pedagogo embrutecedor, segundo a qual o aluno deve apreender aquilo que o mestre faz apreender. Ao contrário, escreve que "os espectadores veem, sentem e compreendem alguma coisa à medida que compõem seu próprio poema, como o fazem, à sua maneira, atores ou dramaturgos, diretores, dançarinos ou performers" (RANCIÈRE, 
REVISTA DO PROGRAMA DE PÓS-GRADUAÇÃO EM COMUNICAÇÃO, LINGUAGENS E CULTURA DA UNIVERSIDADE DA AMAZÔNIA

2012, p. 18). Decorre disso que a noção de literatura, como um sistema de comunicação, permite que o leitor passe a ter papel importante para fazer o texto da sua própria maneira.

Assim, o reconhecimento tem relação direta com a cultura e com as imagens - sobretudo, os estereótipos - construídas por meio da arte e da literatura. O protagonismo e o processo de empoderamento que se observa no leitor leva a literatura para mais próximo do leitor, fazendo com que ela passe a refletir os problemas sociais daquela comunidade de leitores, até porque o escritor deixa de escrever para um leitor ideal e passa a pensar nas realidades do seu leitor real.

Desta luta por reconhecimento surge, na teoria literária, uma corrente de pensamento crítico que traz o leitor de volta ao centro dos estudos literários, assim como Proust, que defendeu um novo papel para o leitor, que vai além de apenas compreender o livro, mas o de compreender a si mesmo através do livro, já que o leitor consegue aplicar o que leu a sua vida, porque a leitura vai além de descoberta, ela também é ensinamento de coisas simples e cotidianas que podemos levar para a vida toda. Em O Tempo Redescoberto, Proust (apud COMPAGNON, 2003, p. 145) escreve: "a escritura é descrita como a tradução de um livro interior, e a leitura como uma nova tradução num outro livro interior".

É interessante essa afirmação, pois nos faz refletir sobre a escrita do autor, já que quando o autor escreve, é impossível que seja imparcial. Ele acaba imprimindo suas impressões, experiências, fatos que aconteceram com ele. O leitor, por sua vez, vê nessa experiência, nessa vivência lida, no texto, algo aplicável para a sua vida. Se fizermos a comparação de uma vida com um livro, podemos dizer que uma vida é um livro aberto e que a experiência de uma pessoa é o que preenche as páginas deste livro. Então, cada um de nós, leitores, temos um livro interior. Após a visão de leitor de Proust, várias outras abordagens teóricas passaram a valorizar o leitor, como a hermenêutica, que buscava perceber o sentido pelo leitor.

Exatamente da abordagem hermenêutica é que chegamos ao conceito de recepção. Uma palavra que parece ser bastante clara e transparente, recepção, ou seja, impressões que alguém recebe de alguma coisa. Em outras palavras, aquilo que o leitor adquire, recebe, absorve, até mesmo a reação/efeitos em função do que leu, podendo essa recepção ser dada por um indivíduo ou por um conjunto de 
pessoas que leram a mesma obra literária.

Esse ato parece ser natural na atualidade, ao se falar em leitura. No entanto, se não fossem as lutas travadas pelos teóricos da Escola de Constança pelo reconhecimento do leitor na experiência estética, talvez a visão de antes ainda permanecesse, em que a recepção era vista não sob a forma de leitura, mas em relação a uma obra motivar a criação de outras obras, medindo-se o destino de uma obra pela sua influência.

Arecepçãopodeser dividida em duas categorias: afenomenologia, que cuida do ato individual da leitura, e a hermenêutica, que cuida da resposta pública (coletivo) ao texto. Para as duas concepções, o tempo real é importante porque o objeto literário não é nada mais do que uma matéria no espaço graças à imprensa, um volume ocupando uma prateleira da estante, configurando-se texto somente no ato da leitura ou enquanto este ato puder durar.

Para a escola de Constança o texto literário propicia ao leitor, a ampliação ou modificação do seu horizonte de expectativas e, assim, sua visão de mundo, não só no plano estético como no plano ético. Jauss (1994, p. 50) acredita que "a experiência literária do leitor adentra o horizonte de expectativa de sua vida prática, pré-formando seu entendimento do mundo e, assim, retroagindo sobre seu comportamento social".

A práxis estética para Jauss (1994) deve ser fundada em três atividades, a produtora, a receptiva e a comunicativa, que Zilberman (1989, p.113) define como:

\footnotetext{
Fruto do relacionamento da obra e o leitor é o aspecto fundamental da teoria fundada na recepção. Compõese em três etapas, inter-relacionadas: a poiesis, pois o recebedor participa da produção do texto; a aisthesis, quando este alarga o conhecimento que o destinatário tem do mundo; e a katharsis, durante a qual ocorre o processo de identificação que afeta as possibilidades existenciais do leitor.

(...) Identificação equivalente à resposta do leitor quando da experiência estética e tem um significado tanto intelectual quanto afetivo.
}

Chegamos, assim, às noções de autor implícito e a de leitor implícito. $\mathrm{O}$ autor, por passar suas experiências dentro da obra, ele nunca se retira por completo, trazendo à tona o autor implícito, um narrador da história, que vai descrevendo os cenários e hipnotizando o leitor, 
personagens, dando emoção ao leitor.

Wolfgang Iser (1996), em seu livro O ato da leitura, afirma que a obra literária só se torna algo real com a interferência do leitor, pois funciona com vários sentidos, acrescentando, assim, aos estudos de Jauss (1994), a teoria do efeito estético. "O sentido do texto é apenas imaginável, pois ele não é dado explicitamente; em consequência, apenas na consciência imaginativa do receptor se realizará" (ISER, 1996, p. 75).

Assim, na teoria de Iser (1996) o leitor assumirá um ponto de vista mediado pelo texto para preencher seus vazios. Iser refere-se ao leitor implícito, que não tem existência real, mas que se funda na estrutura do texto (ISER, 1996, p. 73). Esse leitor enfatiza os efeitos do texto e proporciona a atualização histórica e individual da obra, de acordo com as suas vivências e compreensões introduzidas na leitura (ISER, 1996, p. 78).

Essa interferência ocorre porque o texto literário não é claro, ele é uma obra aberta que instiga o leitor a imaginar o que o autor quisera dizer, aplicando ao texto o seu conhecimento extralinguístico, afim de dar, ao texto, um sentido.

Desta forma, podemos dizer que a leitura é a reunião dos dados fornecidos pelo autor real e o autor implícito ao leitor real, que por sua vez, recebe auxílio do leitor implícito. Ou, conforme Compagnon (2003, p. 152): "o ato da leitura consiste em concretizar a visão esquemática do texto [...], construir uma coerência a partir dos elementos dispersos e incompletos. A leitura se apresenta como uma resolução de enigmas".

No livro “O Rumor da Língua”, Barthes escreve:

toda a leitura se passa no interior de uma estrutura (nem que seja múltipla, aberta), e não no espaço pretensamente livre de uma pretensa espontaneidade: não há leitura natural, selvagem: a leitura não excede a estrutura; submetesse-lhe: precisa dela, respeita-a, perverte-a. A leitura seria o gesto do corpo (pois é claro que lemos com o corpo) que, com um mesmo movimento, funda e perverte a sua ordem: um suplemento interior de perversão (BARTHES, 2012, p. 33).

Barthes (2012) nos fala de uma obra múltipla e aberta, característica também defendida por Eco (2005) e Iser (2011), que irá falar em "lugares vazios" que uma obra possui, para serem 
preenchidos pelo leitor, esses espaços trazem o leitor para dentro da obra de forma que ele crie suas expectativas, ou seja, aja dentro da obra, sendo assim guiado pelo o texto.

Em outras palavras, é como, em uma cidade, que os engenheiros constroem várias vias interligadas, de certa forma, até o centro da cidade. Cada motorista pode seguir a via que quiser. No entanto, todas ligam ao centro. Assim imaginemos que o engenheiro é o autor, as vias são os vazios e que os motoristas são os leitores.

Os lugares vazios omitem as relações entre as perspectivas de apresentação do texto, assim incorporando o leitor ao texto para que ele mesmo coordene as perspectivas. Em outras palavras, eles fazem com que o leitor aja dentro do texto, sendo que sua atividade é ao mesmo tempo controlada pelo o texto. (ISER, 2011, p. 107)

Os lugares vazios, que resultam, portanto, da indeterminação do texto, não exigem complementações, mas indicam uma demanda de trabalho, e desse modo estimulam o leitor. Eles designam a possibilidade de a construção do leitor ocupar um determinado lugar no texto. As conexões em textos ficcionais são interrompidas pelos lugares vazios, que abrem uma multiplicidade de possibilidades de combinações a serem feitas pelo leitor.

O leitor, que por bastante tempo foi ignorado, passa a ter liberdade interpretativa sobre o texto porque ele se torna a peça principal do jogo - é nele que está o segredo do significado do texto, já que ele possui um repertório, um conhecimento externo ao texto aplicado à obra para preencher as lacunas que o autor determinou. Uma obra literária não pode ter somente uma peça principal, mas sim um conjunto, e, no caso em questão, três: o leitor, o texto e o autor. Respeitando as funções desta tríade, o leitor pode continuar a ser livre para produzir o sentido do texto, dentro de uma liberdade permitida.

\section{O LEITOR E A LEITURA HOJE}

O reconhecimento do sujeito leitor no ensino da leitura literária é relativamente recente, nos discursos e ainda longe de ser efetivo nas salas de aula. Ainda hoje, segundo Rouxel (2014), a realidade das aulas do ensino básico e mesmo, às vezes, na educação infantil, a leitura exigida repousa sobre uma série de observações formais que embrutecem o crescimento pessoal do leitor. O texto lido e estudado é quase sempre 
um pretexto à descoberta e aquisição de ferramentas de análise e, então, objeto de uma rotina desencarnada que deixa "fora de jogo" o leitor enquanto sujeito.

Os alunos não leem mais, eles aprendem a identificar o jogo de focalizações, o estatuto do narrador intra ou extradiegético, o discurso indireto livre, as figuras de estilo. Eles elaboram o esquema actancial sem exprimir seu julgamento sobre tal personagem etc. A descoberta desses saberes que permitem, não se pode contestar, uma leitura mais refinada das obras, se faz paradoxalmente em detrimento de uma leitura que interrogasse as questões postas. Portanto, convém perguntar qual leitor se quer formar? Espera-se formar um leitor escolar, mais ou menos experiente, capaz de responder às questões, dominando o tempo dos estudos com certo número de conhecimento factuais e técnicos, ou um leitor de literatura(s), que lê para si, para pensar, agir e se construir, e que se envolve em uma relação durável e pessoal com a literatura? Finalmente, o que está em jogo nessa alternativa é exatamente a finalidade do ensino da literatura em termos de formação do leitor. (ROUXEL, 2014, p.20-21)

O leitor a partir do ato de ler, dá movimento e vida à literatura, aceita o desafio, que lhe compete, de desvendar um conjunto de enigmas que o texto apresenta, por intermédio da interação entre o texto e ele mesmo, produto da própria leitura. Por isso, devemos ir em busca de uma nova luta, a da valorização do leitor na sala de aula.

Portanto, valorizando o leitor, a literatura passaria a ser uma forma de garantir algum equilíbrio social: "ela é fator indispensável de humanização, e, sendo assim, confirma o homem na sua humanidade, inclusive porque atua em grande parte no subconsciente e no inconsciente" (CANDIDO, 1995, p.242). Este seu poder é de natureza perturbadora, pois não há controle sobre as forças movidas pela literatura, que podem ir contra as mais diversas direções que alimentam o sistema de ensino.

Afinal, nada melhor do que um aluno possuir memória de um livro que estudou, pois isso representa, na verdade, a experiência que ele adquiriu com a leitura daquela obra, em que cada leitor nada mais é do que um leitor de si mesmo, de acordo com a sua visão de mundo, que se constrói com a leitura. Na verdade, "o leitor é livre, maior, independente: seu objetivo é menos compreender o livro do que compreender a si mesmo através do livro; aliás, ele não pode compreender um livro se não se compreender ele próprio graças a 
esse livro." (COMPAGNON, 2003, p. 144).

A esse pensamento de Compagnon (2003), soma-se a teoria política de Rancière (2009) que, ao falar da eficácia estética, nos diz tratar-se de uma eficácia paradoxal, referente a uma separação entre as formas sensíveis de produção da arte e seus efeitos nas formas sensíveis de recepção da mesma. Dessa forma, consubstancia-se numa ruptura estética que permite abolir a visão segundo a qual existem homens de inteligência ativa que dominam outros de passividade material. Tornase também uma mudança de ordem política à medida que abandonam a divisão da sociedade em grupos destinados à obediência e outros ao comando.

Para Rancière, a salvação está na obra de arte pensativa, aquela que nos permite uma múltipla visão sobre a arte, expandindo os horizontes possíveis de interpretações - perspectiva esta que pode ser complementada com o pensamento de Umberto Eco (2005), para quem toda obra de arte é aberta a um leque ilimitado de leituras possíveis, reguladas pelo texto. Mais uma vez, comprova-se que a literatura não deve configurar como um objeto, mas sim o que acontece quando lemos.

Precisamos ter consciência de que a leitura e o leitor emancipado para realizarem essa leitura, são a melhor estratégia de ensino que podemos ter, já que deixamos de embrutecer nossos alunos e criamos leitores livres, que se sentirão à vontade ao manusear um livro, pois não sofreram opressão diante de suas leituras e, por isso, se sentirão íntimos com as histórias que leem.

\section{ALGUMAS CONSIDERAÇÕES}

O sistema literário, durante muito tempo, não valorizou o leitor como um ser presente para que a economia literária funcionasse. Durante séculos, o que se prenunciou foi a importância do livro, texto literário como influenciador do leitor.

O leitor, quando lembrado, era colocado como aquele ser vazio que facilmente poderia ser manipulado pelo texto literário, ou como aquele que deturpava a literatura, pois sua leitura nunca conseguia chegar àquela esperada, de um leitor ideal, ou até mesmo quando comparado a outro ser real como o escritor, era colocado em um patamar de inferioridade, pois nunca possuía a ação, era sempre o agente paciente, que só recebe a ação.

A mudança aconteceu com a emancipação do leitor que, por meio de novas teorias, como a estética da recepção, passou a ser valorizado e 
REVISTA DO PROGRAMA DE PÓS-GRADUAÇÃO EM COMUNICAÇÃO, LINGUAGENS E CULTURA DA UNIVERSIDADE DA AMAZÔNIA

colocado em patamar de reconhecimento. É certo que muitas críticas surgiram a esta teoria, que passou a substituir a importância do autor e da obra pela importância do leitor. Para alguns, o leitor passou a ser alvo principal, porém a verdadeira contribuição desta teoria é a de valorização do leitor junto ao texto literário, passando assim a ocupar a mesma posição de prestígio que os outros elementos da literatura possuíam.

Essa luta de reconhecimento do leitor, porém, não poderia acontecer sem uma contribuição social. Neste caso, a maior contribuição está relacionada ao ensino de literatura, onde ainda predomina a análise baseada no texto e no autor. Talvez a grande mudança da realidade do nosso país quanto à falta de leitores literários resulta de uma mudança de perspectiva do ensino de literatura.

Muitas experiências de leituras seguindo esse caminho já aconteceram, muitas metodologias foram pensadas como o Letramento Literário e os Círculos de Leitura (Colson, Dalvi entre outros) e as experiências com base estéticas (Rouxel, Reis et all entre outros), porém a realidade de leitura, principalmente a literária ainda não sofreu reflexos na sala de aula, para isso é preciso que essas experiências extrapolem as pesquisas acadêmicas, e cheguem nos currículos universitários, para assim chegarem aos alunos.

Já que as outras formas de ensinar literatura / leitura não obtiveram resultados eficazes, por que não testar um ensino pela recepção, em que o leitor teria a liberdade de perceber que a obra de arte é pensativa e aberta a sua múltipla interpretação e livre para se encaixar ao horizonte de experiências do leitor? Neste sentido, Compagnon (2003) nos diz que "a experiência da leitura", como toda experiência humana, é fatalmente uma experiência dual, ambígua, dividida: entre compreender e amar, entre a filosofia e a alegoria, entre a liberdade e a imposição, entre aatenção ao outro e a preocupação consigo mesmo.

\section{REFERÊNCIAS}

BARTHES, Roland. O rumor da língua. São Paulo: WMF; Martins Fontes, 2012.

BENJAMIN, Walter. O Narrador - considerações sobre a obra de Nicolai Leskov. In: Magia e Técnica, Arte e Política. Obras Escolhidas I. Trad. Sérgio Paulo Rouanet. São Paulo: Brasiliense, 1994.

CANDIDO, Antônio. O direito à literatura in: Vários escritos. $3^{\mathrm{a}}$ ed. São Paulo: Duas Cidades, 1995. 
COMPAGNON, Antoine. O Demônio da teoria: literatura e senso comum. Trad. Cleonice Paes Barreto Mourão. Belo Horizonte: UFMG, 2003.

ECO, Umberto. Obra A berta: formas e indeterminação nas poéticas contemporâneas. Trad. Sebastião Uchoa Leite. São Paulo: Perspectiva, 2005.

ISER, Wolfgang. $O$ ato de leitura: uma teoria do efeito estético. Trad. Johannes Kretschmer. São Paulo: Ed. 34, 1996.

ISER, Wolfgang. "O Jogo do texto". In: LIMA, Luiz Costa (org.). A Literatura e o Leitor. Rio de Janeiro: Paz e Terra, 2011.

JAUSS, Hans Robert. A História da Literatura como Provocação à Teoria Literária. São Paulo: Ática, 1994.

MEAD, George. Mind, self and society. Chicago: University Of Chicago Press, 1967.

RANCIÈRE, Jacques, A Partilha do Sensível. São Paulo: Editora 34, 2009.

RANCIÈRE, Jacques. O espectador emancipado. São Paulo: WMF; Martins Fontes, 2012.

REIS, Wellingson Valente dos; CASTRO, José Guilherme de Oliveira; TEIXEIRA. Lucilinda Ribeiro. Rito de passagem da vida: a recepção de Maria Lúcia Medeiros por alunos do Instituto Federal do Pará. Cadernos de Pesquisa (UFMA). São Luís, v.25, n.2, p. 225-242, abr./jun. 2018. Disponível em: http://www.periodicoseletronicos, ufma.br/index.php/cadernosdepesquisa/issue/view/470/showToc. Acesso em $30 \mathrm{de}$ outubro de 2019.

ROUXEL, Annie. Ensino da Literatura: experiência estética e formação do leitor. In: ALVES, José Helder Pinheiro, (org). Memórias da Borborema 4. Campina Grande: Abralic, 2014.

ZILBERMAN, Regina. Fim do Livro, fim dos leitores? São Paulo: Editora Senac, 2000 .

ZILBERMAN, Regina. Estética da recepção e história da literatura. São Paulo: Ática, 1989.

Recebido em 27 Set 2019 | Aprovado em 01 Nov 2019

Wellingson Valente dos REIS

Doutorando e Mestre em Comunicação, Linguagens e Cultura pelo PPGCLC da Universidade da Amazônia (UNAMA). Bolsista Prosup/ Capes. Membro do Grupo Interdisciplinar de Pesquisa em Arte, Cultura e Educação (GIPACE - IFPA) e do Grupo de Pesquisa Interfaces do Texto Amazônico (GITA - UNAMA). Professor do Instituto Federal do Pará - Campus Belém (IFPA). E-mail: wellingson.valente@ifpa.edu.br.

José Guilherme de Oliveira CASTRO

Doutor em Letras (PUC - RS). Professor e Psicólogo. Titular do Programa de Pós-Graduação em Comunicação, Linguagens de Cultura (PPGCLC) da Universidade da Amazônia. Líder do Grupo de Pesquisa Interfaces do Texto Amazônico (GITA). Atua pesquisando os seguintes temas: narrativa, conto fantástico, sociedade, imaginário amazônico e lirismo. E-mail: zevone@superig.com.br.

NOTA

O presente trabalho foi realizado com apoio da Coordenação de Aperfeiçoamento de Pessoal de Nível Superior - Brasil (CAPES) - Código de Financiamento 001 